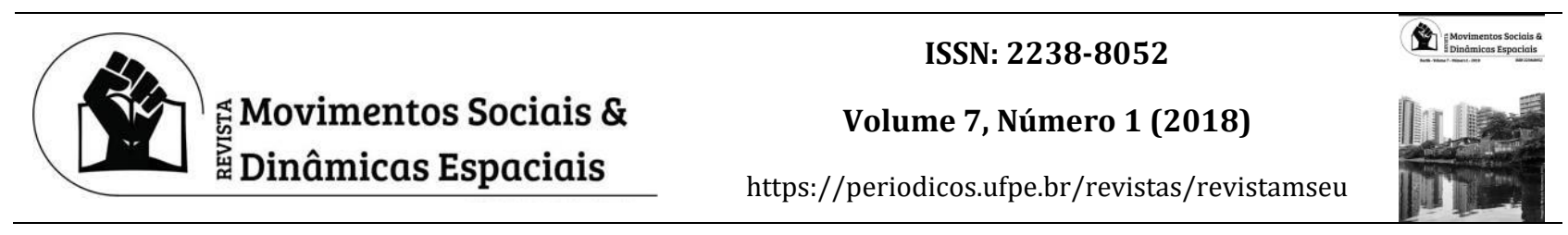

\title{
MUDANÇAS CLIMÁTICAS, EVENTOS EXTREMOS E DESLOCADOS AMBIENTAIS: CASO PALMARES/PE
}

\author{
CLIMATE CHANGE, EXTREME EVENTS AND ENVIRONMENTAL DISPLACED: PALMARES/PE \\ CASE
}

\author{
Afonso Feitosa REIS NETO ${ }^{1}$ \\ Sofia Oliveira de Barros CORREIA ${ }^{2}$ \\ Stevam Gabriel ALVES 3 \\ Werônica Meira de SOUZA 4 \\ Josiclêda Domiciano GALVÍNCIO ${ }^{5}$ \\ Maria do Socorro Bezerra de ARAÚJO6
}

Palavras-chave:

Enchente;

Desastres naturais;

Migração ambiental.

Keywords:

Flood;

Natural disasters;

Environmental

migration.

\section{R E S U M O}

O estudo das mudanças climáticas auxilia na identificação de eventos extremos e nas suas possíveis consequências para a sociedade. Este trabalho teve como objetivo analisar se o evento meteorológico extremo que ocorreu em Palmares/PE, em junho de 2010, ocasionou o surgimento de refugiados e/ou deslocados ambientais. Para atingir o objetivo proposto foi utilizado o software Climap para analisar os dados meteorológicos, assim como convenções e protocolos da Organização das Nações Unidas que disciplinam a temática das migrações de populações por causas ambientais. Além destes, também foram consultados artigos científicos e informações jornalísticas sobre o episódio ocorrido no estado de Pernambuco. Os resultados indicaram que a precipitação pluviométrica ocorrida à época foi um evento extremo que se diferenciou totalmente dos registros históricos já observados ao longo da série de dados (1964 a 2014), e que em Palmares/PE parte dos indivíduos que saíram do município podem ser considerados deslocados ambientais e não refugiados ambientais.

\begin{abstract}
A B S T R A C T
The study of climate change helps to identify extreme events and their possible consequences for society. This study aimed to analyze the extreme weather event that occurred in Palmares/PE, in June 2010, resulted in the emergence of environmental refugees and/or displaced. To achieve this purpose was used the Climap software to analyze meteorological data, as well as conventions and protocols of United Nations that approach the migration of populations for environmental causes. In addition, were also
\end{abstract}

\footnotetext{
1 Doutorando do Programa de Pós-Graduação em Desenvolvimento e Meio Ambiente da Universidade Federal de Pernambuco (PRODEMA/UFPE); Universidade Federal de Pernambuco-UFPE, Recife-PE. E-mail: afonsofeitosa@hotmail.com (autor correspondente).

2 Doutoranda em Desenvolvimento e Meio Ambiente (UFPE). E-mail: sofiabarroscorreia@gmail.com.

3 Doutorando em Desenvolvimento e Meio Ambiente (UFPE). E-mail: stevam_gabriel@hotmail.com.

4 Professora do PRODEMA/UFPE e da Unidade Acadêmica de Garanhuns da Universidade Federal Rural de Pernambuco (UAG/UFRPE). Professora do PRODEMA/UFPE. E-mail: weronicameira@gmail.com.

5 Professora do quadro permanente do Programa de Pós-Graduação em Desenvolvimento e Meio Ambiente (PRODEMA) da UFPE e do Departamento de Ciências Geográficas (UFPE). E-mail: josicleda@hotmail.com.

6 Pós-doutorado pela School of Environmental Sciences, University of Guelph, Canadá. Professora Associado II da Universidade Federal de Pernambuco e Membro do Programa em Rede de Pós-graduação em Desenvolvimento e Meio Ambiente. E-mail: socorro@ufpe.br.
} 
consulted scientific articles and news information about the episode occurred in the state of Pernambuco. The results indicated that precipitation occurred at the time was an extraordinary event that fully differentiated historical period average and that in Palmares/PE part of the population left the city is considered displaced environmental and not environmental refugees.

\section{INTRODUÇÃO}

As mudanças climáticas globais consistem em alterações no clima em todo o mundo, composto a partir da intervenção humana num processo de aceleração de uma dinâmica natural preexistente por meio de atividades que interferem no equilíbrio desse sistema (BARBOSA et al., 2016). Essas modificações podem aparecer de diversas maneiras para os seres vivos, desde o aumento da temperatura em algumas regiões até a mortandade da biodiversidade. Tais eventos ambientais trazem consigo uma séria de implicações que ultrapassam a relação biológica entre meio físico e a biota.

Nessa conjuntura, a sociedade do risco, descrita por Beck (2010), só vem a se preocupar com tais alterações a partir do momento em que ela é diretamente afetada (negativamente) por esses eventos, assumindo dessa maneira uma postura reativa aos acontecimentos. Não obstante tal constatação, as consequências resultantes das mudanças do clima transcendem a mera análise ambiental do evento em si, exigindo daqueles que as estudam um estudo interdisciplinar, perpassando sobre as três vertentes descritas por Milaré (2015): natural, social e cultural.

As modificações dos sistemas ambientais promovem vulnerabilidades em determinadas populações. A vulnerabilidade ambiental ocasiona o surgimento de categorias, ainda não reconhecidas juridicamente, de pessoas que são forçadas a abandonar os seus locais de origem por conta de graves distúrbios causados por problemas que envolvem o meio ambiente, os chamados refugiados e os deslocados ambientais (WESTRA, 2009). Os referidos grupos enfrentam lacunas na ordem jurídica, no plano interno e externo, que dificultam a sua proteção. Além destas, a própria conceituação ainda é obscura frente aos pesquisadores da temática.

Ramos et al (2011) faz importante reflexão sobre o conceito de refugiados ambientais, realizando pertinente contextualização deste processo para o caso brasileiro, apontando as fragilidades e lacunas que permanecem nos dispositivos jurídicos e políticos globais e locais para salvaguardar essas pessoas que sofrem com as catástrofes ambientais, sejam elas de cunho predominante antrópico ou não. Para além da diferenciação do conceito de refugiado e deslocado ambiental, ou seja, mais do que a delimitação espacial para que a denominação seja atribuída, é necessária para sanar o obscurantismo que existe nesta conjuntura, por exemplo, o reconhecimento dos fatores ambientais como motivadores de perseguição, como elementos geradores de conflitos de diversas ordens, o que enquadraria os refugiados ambientais como refugiados juridicamente reconhecidos e resguardados pelo Estatuto dos Refugiados. 
Então, a ideia de contribuir com a presente discussão significa buscar aprofundamento e esclarecimento sobre tais conceitos e sobre todo o arcabouço gnosiológico que os envolve e os faz em efetivas ações de proteção aos refugiados e deslocados ambientais, que, atualmente, se encontram em situação incerta e frágil no que tange aos Direitos Locais, Regionais e Internacionais.

No Brasil, a interferência das mudanças climáticas se expressa, principalmente, com o aumento de temperatura em todo o país e por meio das precipitações atingindo extremos (chuvas torrenciais e estiagens severas). Em Pernambuco não é diferente, de grande porção sujeita a processos de desertificação e com regiões que estão abaixo do nível do mar, o Estado se apresenta como um local vulnerável aos eventos meteorológicos extremos, ocasionando deslocamentos populacionais em razão das condições climáticas. Exemplo de evento meteorológico extremo ocorreu no ano de 2010 quando o município de Palmares/PE (entre outros da região) enfrentou uma grande enchente, resultando no deslocamento de uma massa populacional que foi obrigada a retirar-se do seu local de moradia.

Nesse sentido, em razão da sua multifacetária análise acerca dos eventos extremos juntamente com a temática dos refugiados/deslocados ambientais, se faz necessária a constante produção de conhecimentos, sob o paradigma da complexidade, que trazem abordagens atualizadas sobre extremidades ambientais, possíveis consequências materiais e imateriais destes, assim como sobre a capacidade de resposta e de adaptação que as cidades, suas populações, possuem para estes acontecimentos.

Dessa forma, esse artigo possui como objetivo analisar se o evento meteorológico extremo que ocorreu em Palmares/PE, em junho de 2010, ocasionou o surgimento de refugiados e/ou deslocados ambientais. Destaca-se que não se pretende exaurir a discussão e sim trazer uma nova perspectiva interdisciplinar para o fenômeno em destaque.

\section{MATERIAL E MÉTODOS}

\section{1 Área de estudo}

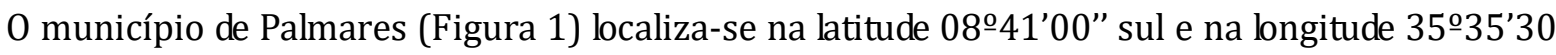
oeste, estando a uma altitude de 125 metros. Fica localizado na região da Mata Sul, Zona da Mata Pernambucana. Sua população estimada em 2015 é de 62.020 habitantes. A sede do Município dista $104 \mathrm{~km}$ em linha reta e $118 \mathrm{~km}$ pela BR-101 do Recife, a capital do Estado; $105 \mathrm{~km}$ de Garanhuns e 123 km de Maceió, a capital do de Alagoas. 
Figura 1. Localização do município Palmares no estado de Pernambuco.

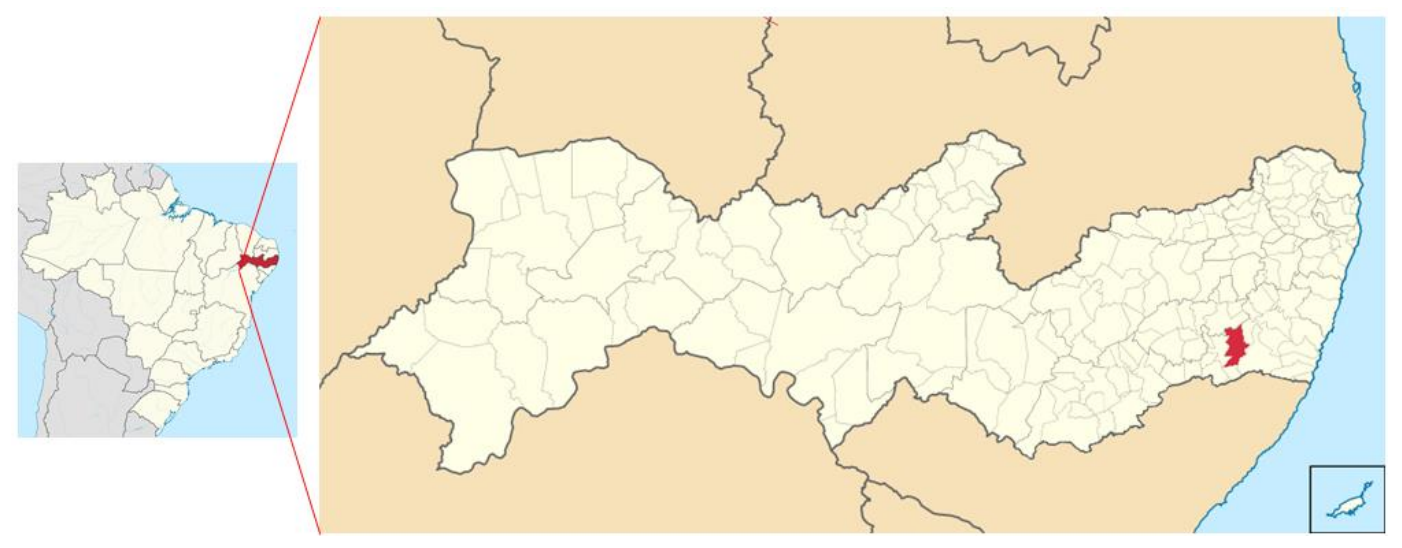

Fonte: IBGE, adaptado pelo autor, 2015.

O clima é tropical úmido com deficiência hídrica no verão e excedente hídrico no inverno, a média pluviométrica histórica (média obtida em uma série de dados meteorológicos com no mínimo 30 anos de observações) é de 1.752 mm (SOUZA; MACIEL NETTO; AZEVEDO, 2012). A topografia, predominantemente ondulada, caracteriza-se por um conjunto de morros e colinas com altitudes não superiores a 120 m e pediplanos resultantes do alargamento do vale do rio Una (Pernambuco) e seus afluentes. Em relação à vegetação, o município insere-se no bioma da mata atlântica, apresentando ainda alguns remanescentes de fragmentos florestais (REIS NETO, 2016).

\subsection{Dados pluviométricos}

Tendo em vista que para compor uma avaliação dos padrões de precipitação que identifique alterações no clima de determinada região é preciso à existência de dados por um período mínimo de trinta anos, e ainda, para definir a variabilidade climática é preciso investigar o comportamento diário, mensal e anual do regime de chuvas (BARBOSA et al., 2016), buscou-se para a realização desse trabalho analisar os dados de precipitação pluviométrica do município de Palmares adquiridos através da Agência Pernambucana de Águas e Clima (APAC) referentes ao período de 1960 a 2014, representando uma série histórica de 54 anos. As estações, ambas localizadas no munícipio, foram a de no 25 e a no 415 .

Cabe salientar que a série histórica apresenta falhas nos anos de 1961 (novembro), 1971 (dezembro), 1972 (fevereiro-dezembro), 1989 (maio-outubro), 1991(fevereiro-abril; setembrodezembro), 1992 (janeiro-dezembro). A ausência de dados pode ser atribuída às falhas nas estações meteorológicas, assim como problemas de transmissão das informações para as centrais. Apesar das lacunas presentes, a ausência dos dados não macula a análise, tendo em vista que o presente estudo não se limita apenas ao estudo climatológico e sim uma visão mais ampla. Ademais, os dados do mês de junho de 2010 foram obtidos na íntegra. 
Para tratamento dos dados meteorológicos foi utilizado o software Climap. O Climap 1.1 é um aplicativo com interface gráfica que auxilia a análise de das séries de dados meteorológicos de chuva e de temperatura do ar, com a associação de informações e criação de gráficos A linguagem de programação empregada para seu desenvolvimento foi a de Python 2.7.6, com os recursos de criação de interface gráfica da biblioteca Tkinter, que é um recurso nativo do Python (BARBOSA et al., 2016).

Inicialmente, os dados foram organizados no formato ano/mês/dia/precipitação em forma de tabela utilizando o Microsoft Excel. Posteriormente, foram gerados gráficos para auxiliar na interpretação das informações obtidas, e a partir da análise dos dados numéricos e da visualização dos gráficos iniciais. Os valores da precipitação pluviométrica foram processados no aplicativo Climap 1.1, a fim de gerar explanações mais específicas sobre o comportamento do regime de chuvas na área estudada.

\subsection{Legislação}

No que cabe a temática dos refugiados/deslocados ambientais utilizou-se como documentos norteadores as Convenções e Protocolos internacionais que disciplinam tal temática. Além desses, também foram consultadas informativos e boletins da Organização das Nações Unidas (ONU) que possuem como objetivo a proteção dessa classe de refugiados/deslocados. Por fim também foram examinados artigos científicos, dissertações e teses que abordam tal assunto. No mais, buscando trazer informações complementares ao estudo também foi utilizado como fonte matérias jornalísticas sobre o evento extremo em Palmares/PE. Em posse desses dados, foi feito um cotejo entre esses e a realidade encontrada no Estado, buscando sempre trazer uma visão crítica e holística, sob o enfoque racional do meio ambiente.

\section{RESULTADOS E DISCUSSÃO}

\subsection{Mudanças climáticas e eventos meteorológicos extremos}

O contexto mundial de insegurança gerada frente à discussão sobre as mudanças climáticas em conjunto com as sensações que este cenário incita, requer o delineamento, além da mitigação de riscos que podem ameaçar as populações. Os eventos climáticos e meteorológicos extremos são causadores de riscos sérios, assim como para os riscos, a definição e previsão de tais eventos são prudentes.

Desde 1950, são observadas mudanças tanto nos padrões de ocorrência, quanto na magnitude de eventos meteorológicos e climáticos extremos. Constata-se que tais mudanças são influenciadas pelas ações antrópicas, são algumas delas: a queda das temperaturas baixas extremas, também, o 
aumento das temperaturas altas extremas; o aumento dos níveis dos mares e na ocorrência de precipitações severas em determinadas regiões (IPCC, 2014).

O impacto das mudanças climáticas sobre os eventos hidro-meteorológicos pode ser avaliado por meio de projeções do clima, consistindo em modelos matemáticos que têm como lastro equações e hipóteses razoáveis, partindo de conhecimentos atualizados, mas que não são capazes de sanar, por completo, as incertezas frente ao futuro. Partindo desse tipo de projeção, é provável que as alterações climáticas venham a exercer influências nos seguintes processos: “[...] variação das disponibilidades da água; alteração nos padrões da precipitação e da ocorrência de cheias, de secas e de outros eventos extremos; subida do nível médio do mar; alteração da temperatura média na atmosfera" (ALMEIDA, 2011, p. 27).

A probabilidade estimada para a ocorrência de um evento extremo de origem natural ou antrópica, se associa às características de severidade do mesmo. No caso dos eventos de origem natural de elevada severidade, como as cheias, sua ocorrência tende a ser inversamente proporcional a sua magnitude, ou seja, este tipo de evento é pouco frequente em relação àqueles que são considerados constantes em um determinado local e tempo histórico. A própria história da humanidade confirma esta tendência: “[...] os eventos extremos, com probabilidade de ocorrência muito pequena, tendem a ser de maior severidade podendo esta ser, contudo, limitada superiormente (e.g. o conceito de precipitação máuma determinada região)” (ALMEIDA, 2011, p. 49).

A definição de um evento extremo não é algo simples, além da análise estatística das variáveis que demanda processo, quando o foco é a semântica do termo, envolve o esclarecimento de conceitos correlatos (evento raro, severidade, vulnerabilidade, risco, magnitude, frequência), que são diretamente vinculados às variáveis estatísticas, e do contexto de sua ocorrência. Stephenson $(2008, p$. 12) o define como:

[...] are events that have extreme values of certain important meteorological variables. Damage is often caused by extreme values of certain meteorological variables, such as large amounts of precipitation (e.g., floods), high wind speeds (e.g., cyclones), high temperatures (e.g., heat waves), etc. Extreme is generally defined as either taking maximum values or exceedance above pre-existing high thresholds. Such events are generally rare; for example, extreme wind speeds exceeding the 100-year return value, which have a probability of only 0.01 of occurring in any particular year.

O autor supracitado defende que a análise quantitativa do evento não basta para descrevê-lo, é fundamental considerar um evento meteorológico extremo como um processo multidimensional, o que requer a avaliação de certos atributos, de ordem numérica: taxa de ocorrência (probabilidade por unidade de tempo); magnitude; duração temporal; escala espacial; dependências multivariadas.

De acordo com Marengo (2009), um evento extremo se manifesta como valores discrepantes para as variáveis climáticas, em relação a um estado climático médio, isto, Em escalas temporais que se apresentam em dias, até em milênios. Contudo, os mais impactantes para as atividades humanas são 
aqueles de curto e médio prazos, ou seja, aqueles eventos relacionados ao tempo e ao clima respectivamente.

0 conceito de vulnerabilidade, neste contexto, pressupõe um risco de dano causado às populações, decorrente das mudanças climáticas, seja por eventos meteorológicos ou por climáticos extremos. Como consta no artigo 2º, inciso X, da Política Nacional do Clima, em que os eventos extremos são considerados como fenômenos geradores de vulnerabilidade, definida como:

[...] grau de suscetibilidade e incapacidade de um sistema, em função de sua sensibilidade, capacidade de adaptação, e do caráter, magnitude e taxa de mudança e variação do clima a que está exposto, de lidar com os efeitos adversos da mudança do clima, entre os quais a variabilidade climática e os eventos extremos (BRASIL, 2009).

A capacidade de resposta abarca tanto a atenuação de prováveis danos materiais, como para a infraestrutura das cidades, quanto imateriais: danos à saúde, mortes, perda histórica e o obscurantismo da identidade cultural. Quanto à infraestrutura de transporte, de canalização tanto de água como de energia, uma das soluções seria adaptar o seu design com base na descrição dos eventos extremos possíveis nas cidades (BUCCHIGNANI; GUTIERREZ, 2015).

Na Região Nordeste do Brasil, os desastres oriundos de eventos meteorológicos extremos de precipitação e consequentes inundações e alagamentos bruscos correspondem a 13\% em relação aos eventos de estiagem e inundações graduais, o que configura a população nordestina como vulnerável (ABDN, 2012).

Desta maneira, a definição e previsão de eventos meteorológicos extremos se torna imprescindível para fortalecer a capacidade de resposta da população às consequências deste tipo de evento: danos graves à população e à infraestrutura das cidades que impelem as pessoas a abandonar suas casas, muitas vezes, suas cidades.

\subsection{Caso Palmares/PE}

Eventos extremos tornam-se cada vez mais comum hodiernamente. Explicações para tal frequência vão desde o ciclo natural do planeta até a intervenção direta antrópica nos sistemas ambientais. Não obstante tal discussão, fato é que tais fenômenos ocasionam grandes perdas para as populações diretamente atingidas pelos seus efeitos. No ano de 2010, mais precisamente no mês de junho, o município de Palmares experimentou o grande poder destrutivo que um evento climático pode ocasionar. Em dois dias (17e 18/06) choveu o equivalente a 299,2 $\mathrm{mm}$, sendo a média histórica para todo o mês de 243, 1 mm (APAC, 2016) (Figura 2). 
Figura 2. Média histórica de chuvas no mês de junho no município de Palmares/PE de 1963-2014. Em destaque o ano de 2010.
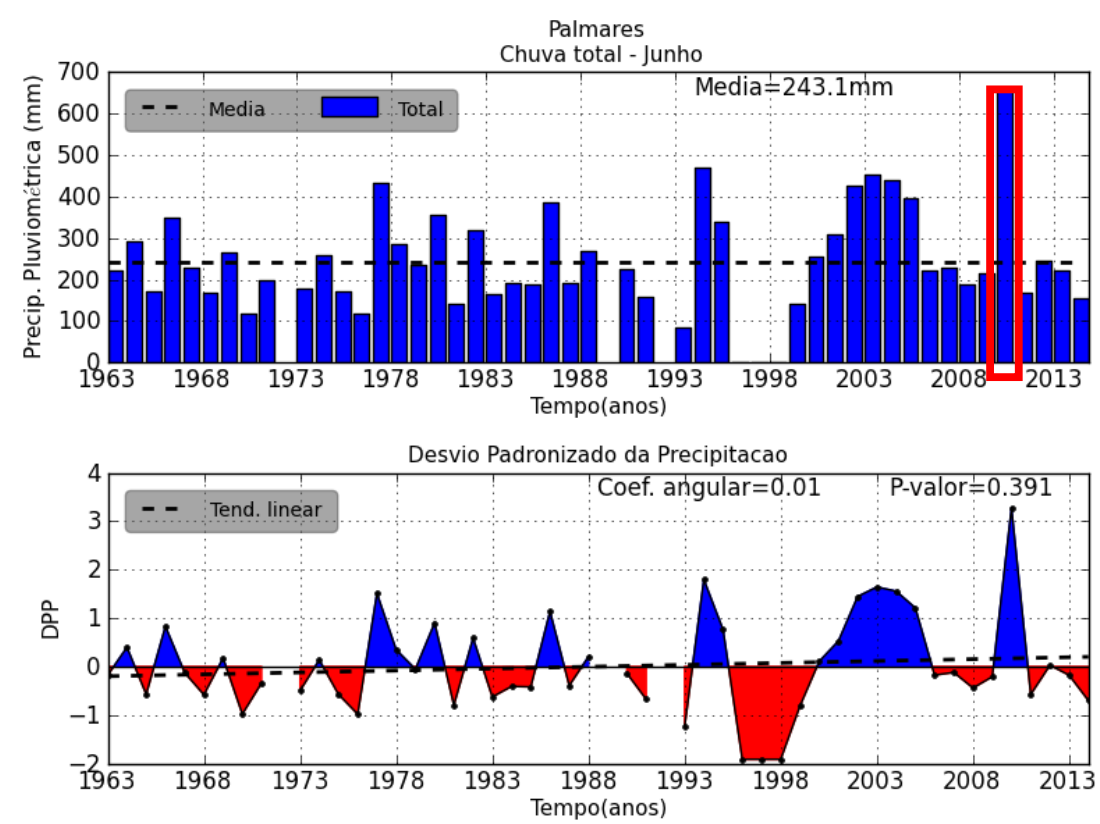

Fonte: APAC (2016)

Observa-se na Figura 2 que no ano de 2010 o mês de junho apresentou grande precipitação pluviométrica, destoando consideravelmente da média histórica do município. Ademais, como já referido anteriormente, a grande problemática causada não foi somente a grande quantidade de chuvas e sim a intensidade de chuvas em um curto espaço de tempo, no caso dois dias. Essa intensidade fez com que o rio Una elevasse seu nível, causando uma grande enchente que devastou todo o trecho da cidade que estava próxima ao rio (Figura 3). De acordo com relatos jornalísticos, ondas de 6 metros atingiram a cidade, onde praticamente tudo ficou debaixo d'agua (BONIN, 2010).

Figura 3. Residências destruídas após a enchente do Rio Una em Palmares/PE.

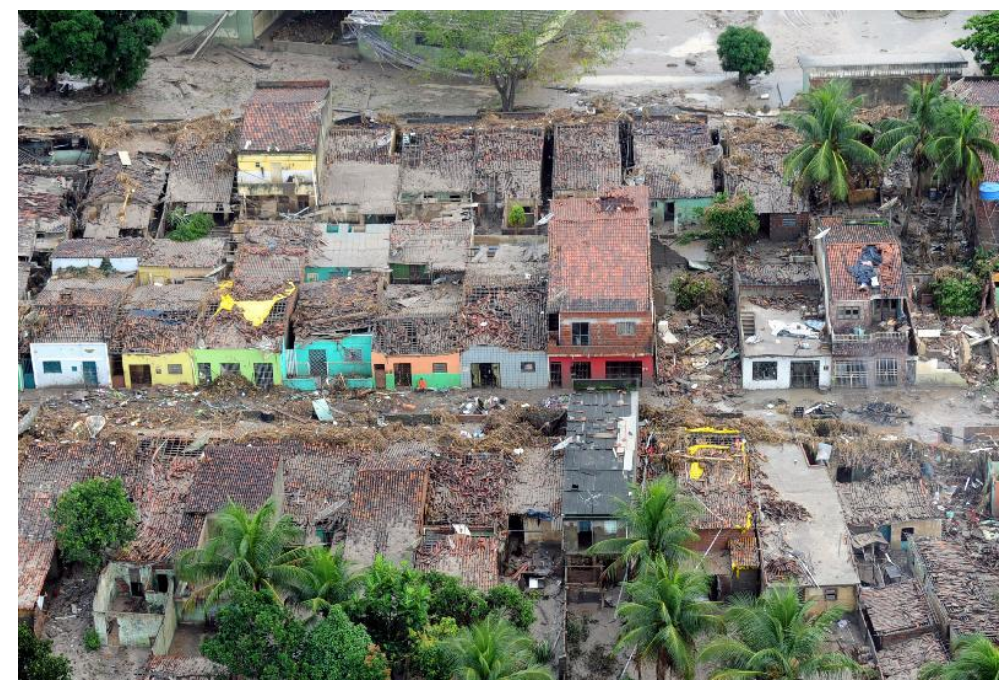

Fonte: EBC (2010). 
Não se pode olvidar que historicamente o mês que apresenta maior índice pluviométrico é de junho (Figura 4), contudo, contrariando todo o estudo climatológico, não se esperava algo tão extremo. O fenômeno climático apontado como principalmente causador das chuvas extraordinárias é a chamada "Onda de Leste", que foi intensificada pelo aquecimento anômalo da temperatura do Oceano Atlântico juntamente com a intensificação dos ventos alísios, provocando, em curto espaço de tempo, uma grande quantidade de chuva concentrada nas proximidades das cabeceiras de vários rios, gerando uma enorme enxurrada que atingiu cidades ribeirinhas nos estados de Pernambuco e Alagoas.

Em números totais, no estado de Pernambuco, foram 16.862 casas destruídas/danificadas; $4.478 \mathrm{~km}$ de estradas destruídas/danificadas; 142 Pontes destruídas/danificadas; 26.966 pessoas desabrigadas7; 55.643 pessoas desalojadas8 (BANCO MUNDIAL, 2010). Vale destacar que Palmares, juntamente com outros nove municípios, o Governo do Estado decretou estado de calamidade pública.

Figura 4. Médias históricas mensais (a) e trimestrais (b) de precipitação pluviométrica em Palmares-PE
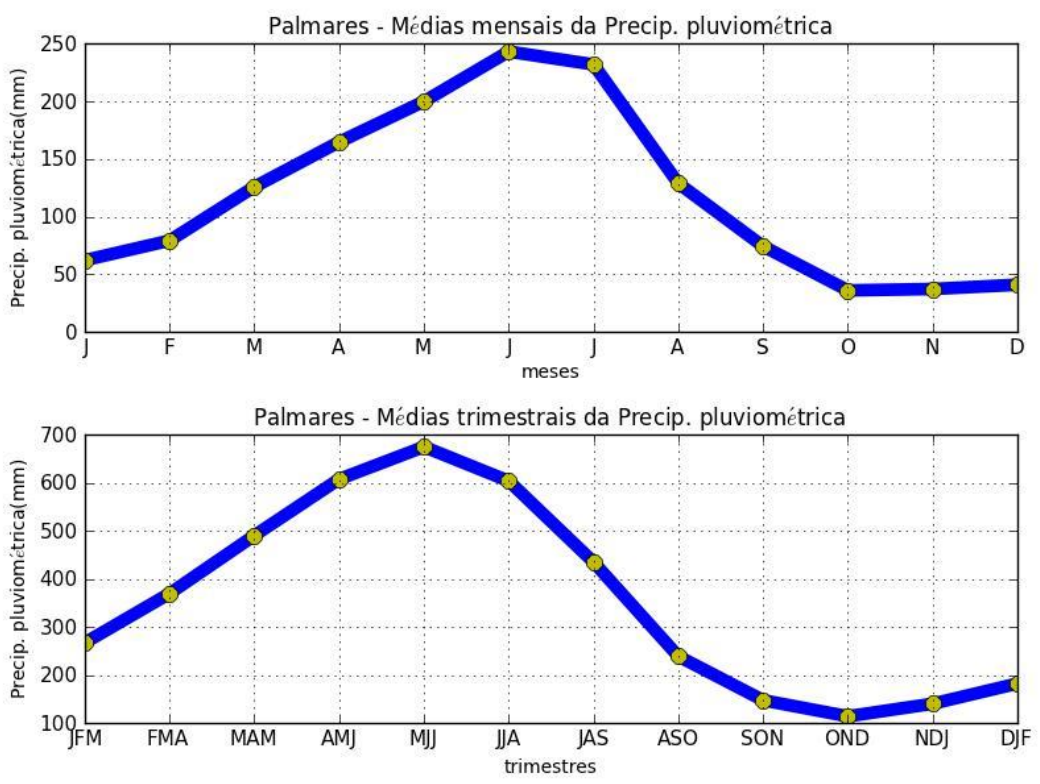

Fonte: APAC (2016).

No gráfico das médias históricas mensais (Figura 4a) nota-se, conforme supracitado, que junho apresenta uma maior precipitação pluviométrica, sendo o mês de outubro a menor precipitação pluviométrica em Palmares. Quando análise é feita por trimestres (Figura 4b), os meses de maiojunho-julho (MJJ) apresentam o maior valor total enquanto o menor é no trimestre outubronovembro-dezembro (OND). Os dados demonstram que o período mais crítico em relação a chuvas é no trimestre MJJ. Não por acaso a maior precipitação acumulado em um dia ocorreu em maio, no ano

\footnotetext{
${ }^{7}$ Pessoa cuja habitação foi afetada por dano ou ameaça de dano e que necessita de abrigo provido pelo governo.

8 Pessoa que foi obrigada a abandonar temporária ou definitivamente sua habitação, em função de evacuações preventivas, destruição ou avaria grave, decorrentes do desastre, e que, não necessariamente, carece de abrigo provido pelo Sistema.
} 
de 2011, quando as estações marcaram 209,06 mm (APAC, 2016). Fato este que desencadeou uma nova enchente em Palmares, com proporções menores a de 2010, mas que ainda sim trouxe uma série de transtornos para o município.

$\mathrm{Na}$ avaliação histórica feita para o número de ocorrências em que existiu chuva com volume maior ou igual a $50 \mathrm{~mm}$ (chuva considerada muito forte), verificou-se que existe uma leve tendência para diminuição desses eventos (Figura 5). Ademais, verifica-se que no ano de 2010 aconteceram apenas cinco dias em que a precipitação foi maior que $50 \mathrm{~mm}$, ratificando mais uma vez a hipótese de que deve-se levar em consideração não apenas os dias com chuva e seu respectivo volume e sim a concentração dessas chuvas em um curto espaço de tempo. Do mesmo modo, no ano de 2011 ocorreram apenas quatro dias de chuvas muito forte.

Figura 5. Número de dias com chuva iguais ou maiores a $50 \mathrm{~mm}$.

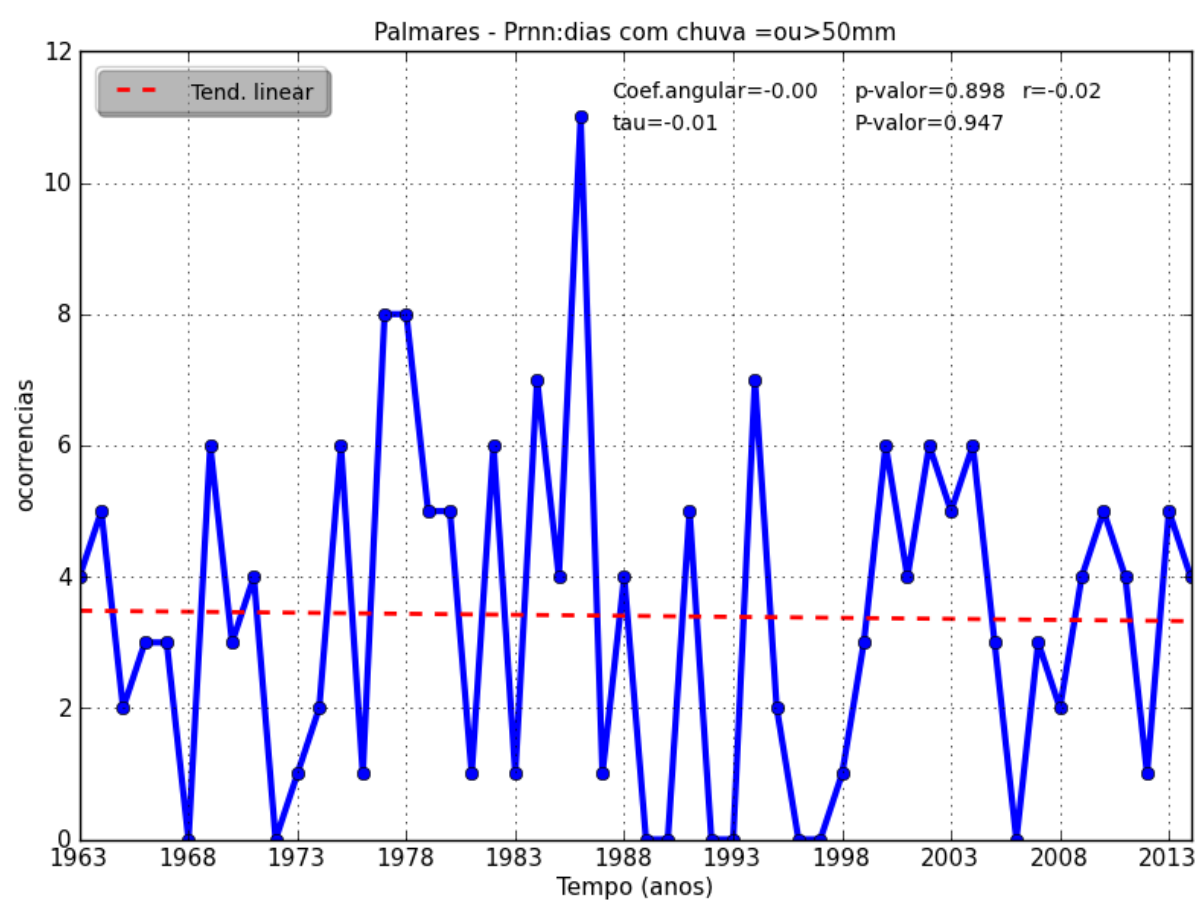

Fonte: APAC (2016).

Quando modificado para número de ocorrências com precipitação $\geq 1 \mathrm{~mm}$ (Figura 6a), $\geq 10$ mm (Figura 6b) e $\geq 20 \mathrm{~mm}$ (Figura 6c) nota-se uma leve tendência da aumento na primeira e leve tendência de redução nas duas últimas. 
Figura 6. Número de dias por ano com precipitação $\geq 1 \mathrm{~mm}(\mathrm{a}), \geq 10 \mathrm{~mm}(\mathrm{~b})$ e $\geq 20 \mathrm{~mm}$ (c) em Palmares-PE.
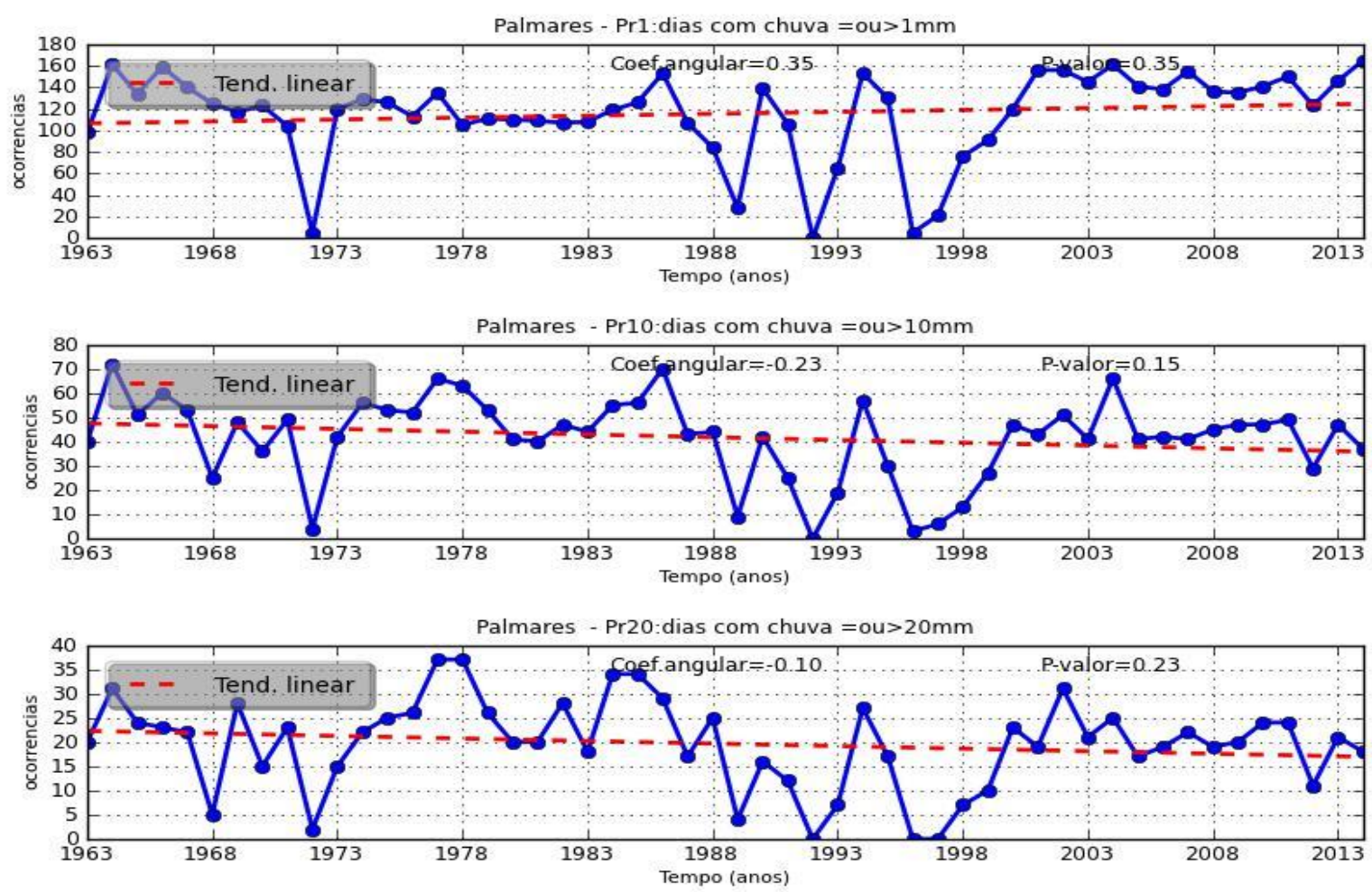

Fonte: APAC (2016).

A previsão de eventos extremos, como a enchente ocorrida em Palmares, é algo ainda difícil de diagnosticar seja em razão de recursos materiais seja pela intensa dinâmica natural do meio ambiente. A partir dos gráficos foi possível verificar que a grande precipitação ocorrida em dois dias, no ano de 2010, foi realmente algo extraordinário e que pelo estudo climatológico não seria possível prever ou até mesmo observar no passado situação similar. Não obstante tal cenário, a principal medida de enfrentamento é a prevenção.

Após a enchente, o Governo do Estado anunciou obras de contenção com projetos de construção de represas para regularizar a vazão desses rios. Todavia, seguindo pelo raciocínio da prevenção, medidas como o reflorestamento de áreas; um melhor manejo e uso do solo; e também a recuperação das margens dos rios que cortam o munícipio, devem ser empreendidas pelo Poder Público de modo que as perdas com futuros eventos extremos sejam minimizadas.

\subsection{Refugiados ou deslocados ambientais?}

Eventos climáticos extremos trazem uma série de problemas de cunho estrutural para os aglomerados urbanos. Destruição de estradas, inundações de cidades, degradação de pontes e equipamentos públicos. Apesar dos prejuízos, todas essas consequências podem ser amenizadas, ou 
até mesmo reparadas, a partir de iniciativas de planejamento e reconstrução frente aos desastres naturais. Todavia, uma grande questão ainda pouco debatida é os movimentos populacionais gerados por esses fenômenos ambientais.

Cabe discutir, portanto, se no caso Palmares houve a caracterização de um deslocamento da população em razão da enchente e se o referido fluxo de pessoas encontra algum tipo de respaldo legal frente às disposições humanitárias da ONU e do ordenamento nacional. Contudo, faz se imperioso determinar as principais concepções sobre refugiados e deslocados ambientais.

Segundo previsão da Convenção das Nações Unidas para o Combate à desertificação (UNCCD, sigla em inglês) a América Latina pode ficar sem 25\% de seu solo agricultável já no ano de 2030 (Fonte). Não obstante essa previsão, os eventos meteorológicos extremos tendem a acontecer em uma frequência cada vez maior. Um dos efeitos imediatos desta situação é, também, o deslocamento de um imenso contingente de pessoas que perderão sua fonte de produção de subsistência e sua moradia. É neste contexto planetário de intensas mudanças climáticas que emerge os denominados refugiados ambientais.

A oficialização se deu com a aprovação da Convenção das Nações Unidas sobre o Estatuto dos Refugiados no ano de 1951. No entanto, a definição de refugiado estava atrelada, predominantemente, a aspectos de raça, conflitos bélicos, religiosos, culturais, ideológicos. 0 questionamento a respeito do conceito clássico de refugiado tem trazido para a discussão outras formas de discriminação, bem como de sofrimentos decorrentes de situações até então ausentes ou, ainda muito pouco evidentes.

No caso dos refugiados ambientais são seres humanos expulsos de suas moradias não por questões políticas, religiosas ou ideológicas, mas, sim, pelas catástrofes ecológicas. Tais catástrofes estão a denunciar, de forma dramática, que vivemos num ambiente planetário. Tal ideia é amplamente difundida no Direito Ambiental, notadamente no estudo de um de seus princípios fundantes, qual seja, a ubiquidade. Segundo esse, que é um dos fundamentos do jusambientalismo, o meio ambiente, e consequentemente os problemas ambientais, não se limitam as fronteiras previamente estabelecidas pelo homem (MILARÉ, 2015).

Feito essa definição preliminar, chega-se a problemática dos refugiados ambientais. Quando ocorre algum desastre natural, os efeitos desse fenômeno podem ser sentidos em outras localidades diferentes da região onde ocorreu o evento extremo. As consequências podem ser de cunho ambiental ou social (PACÍFICO; GAUDÊNCIO, 2015). No primeiro grupo, a depender do tipo de desastre, destacase as alterações na qualidade de água, do ar e do solo. No segundo grupo temos a alteração do perfil econômico da região e, principalmente, os deslocamentos de contingentes humanos. Esse último traço é que serve de plano de fundo para as discussões sobre os refugiados ambientais.

É importante destacar que esse conceito de "refugiados ambientais" é bastante vacilante, principalmente sobre o ponto de vista dos doutrinadores da ciência jurídica, tanto sob o plano 
nacional quanto internacional. Nesse sentido, cabe expor que existem basicamente duas acepções: a de que para ser refugiado faz-se necessário ultrapassar as fronteiras de determinado país e a segunda que o mero deslocamento, independentemente de fronteiras, já preenche a essência da expressão. A definição do termo se faz de grande importância tendo em vista as repercussões legais que dele pode advir.

Para Souza (2010) a situação do refugiado ambiental, ainda que de maneira turva, encontra algum tipo de respaldo no ordenamento jurídico internacional. Os deslocados ambientais é que enfrentam grande dificuldade, pois não possuem nenhum tipo de normatividade específica que lhes confira proteção. De acordo com Oliveira (2010) o deslocamento ou deslocação interna é apenas uma das várias formas de desenraizamento no mundo contemporâneo. Entretanto, é certamente aquela que traz alguns dos maiores desafios para a comunidade internacional. Sua principal característica é que as vítimas, mesmo fugindo de suas regiões de residência habitual, não cruzam uma fronteira internacional.

De acordo com a Convenção sobre o Estatuto dos Refugiados de 1951, refugiado é aquele que:

Art. $1^{\circ}$ (...) em consequência dos acontecimentos ocorridos antes de 1ํ․ de Janeiro de 1951, e devido a fundados temores de perseguição por motivo de raça, religião, nacionalidade, grupo social ou opinião política, encontre-se fora do país de sua nacionalidade e não possa ou não queira acolher-se à proteção desse país; ou que, não tendo nacionalidade e estando fora do país onde antes teve sua residência habitual, não possa, em consequência de tais acontecimentos, ou não queira, devido a tal temor, regressar a ele. (OLIVEIRA, 2010, p. 80).

O documento prescreve os direitos fundamentais dos refugiados e formaliza as regras para seu tratamento. Contudo, mesmo com sua implementação em 1954, os problemas relativos a refugiados persistiram, a despeito da crença de que se extinguiriam com o final da Segunda Guerra. Após 1o de janeiro de 1951, vários conflitos eclodiram, dando origem à movimentação de novos refugiados que não viam a possibilidade de se beneficiarem da Convenção. Em 4 de outubro de 1967, o Protocolo sobre o Estatuto dos Refugiados das Nações Unidas entra em vigor, inserindo uma nova definição para refugiado, que retira a questão da temporalidade expressa na Convenção de 1951, garantindo a qualquer pessoa em condição de refugiado o benefício da proteção.

Ainda segundo Pacífico e Gaudêncio (2015), a explicação do contexto e da natureza da mencionada Convenção requer pensar que, seis anos antes de sua conclusão, a Carta das Nações Unidas (1945) havia identificado os princípios da soberania, da independência e da não interferência dentro do domínio da jurisdição interna de um Estado. Além disso, a Declaração Universal dos Direitos Humanos (1948) reconheceu que todas as pessoas têm direito de procurar e de gozar de asilo em outros países.

Outro diploma legal foi o Protocolo sobre o Estatuto dos Refugiados, de 1967, que surgiu da necessidade de abranger outras pessoas dentro do significado do termo "refugiado", além daquelas 
previstas pela Convenção Relativa ao Estatuto dos Refugiados. 0 protocolo trouxe a lume a consideração de que novas situações de refugiados, no período pós-1951, devem inserir-se no texto da Convenção. Diante disso, segundo o protocolo, o termo "refugiado" deve ser aplicado a qualquer pessoa na definição do artigo $1^{0}$ da mencionada convenção, como se fossem omitidas as palavras: "como resultado de acontecimentos ocorridos antes de 1ำ de janeiro de 1951" e as palavras "um resultado de tais eventos.".

Diante disso, a categoria refugiado abrange toda a pessoa, independentemente do tempo histórico, que seja incapaz de regressar ao seu país de origem devido a um receio fundado de ser perseguida por motivos de raça, religião, nacionalidade, pertencimento a determinado grupo social ou de opinião política. 0 refúgio ambiental significa uma migração forçada e rápida, logo após o evento natural ou logo antes de ele ocorrer, em razão da impossibilidade da vida ou da dignidade, em razão de tal evento.

A expressão ganhou difusão com a publicação, em 1985, de um artigo com este nome, por Essam El- Hinnawi, professor do Egyptian National Research Centre, no Cairo. Consoante Grubba e Mafrica (2015), esse termo refere-se a pessoas que fugiram de suas casas em decorrência de mudanças ambientais que tornaram suas vidas ameaçadas ou insustentáveis. Em alguns casos, essas pessoas encontraram novos lugares para viver em seus próprios países. Em outros, elas necessitaram mudar de um país para outro buscando refúgio.

Em relação aos deslocados ambientais, tem-se o seguinte conceito:

\begin{abstract}
Pessoas ou grupos de pessoas compelidas a fugir de seus domicílios ou dos locais em que residiam habitualmente, particularmente em consequência de, ou com vistas a evitar, os efeitos de conflitos armados, tensões internas, violações de direitos humanos ou desastres naturais ou provocados pelo homem, e que não atravessaram uma fronteira nacional reconhecida internacionalmente. (COMISSÃO DE DIREITOS HUMANOS, 1997, p.39).
\end{abstract}

As duas características determinantes da deslocação interna são o elemento involuntário do movimento de pessoas e a permanência destas dentro das fronteiras de seu país de origem. As pessoas que se deslocam voluntariamente de um lugar para outro por razões econômicas, sociais ou culturais não integram esta definição de deslocados internos (OLIVEIRA, 2010). Para estar em situação de deslocação interna uma pessoa ou grupo de pessoas deve ser compelido a fugir de seu local de residência em razão de conflito armado, de algum tipo de tensão interna, de violações de direitos humanos ou por força de alguma catástrofe provocada pelo homem ou por causas naturais. Além disso, esta pessoa ou grupo de pessoas não pode ter cruzado uma fronteira nacional internacionalmente reconhecida.

De acordo com Souza (2010), ao contrário do que ocorre com os refugiados, os deslocados internos não abandonaram seu país de origem e de cidadania, por isso mantêm os mesmos direitos de que gozam todas as outras pessoas no seu país. Os deslocados são parte da população civil e só se 
diferenciam dos outros cidadãos por estarem em uma situação de maior vulnerabilidade e possuírem necessidades especiais. Assim, tal como se encontra hoje estruturada, a aquisição de direitos pelos deslocados internos não depende de um conceito específico.

A definição existente reflete uma situação fática e não tem a pretensão de conceder um status legal diferenciado para pessoas deslocadas internas. A proteção jurídica, nacional ou internacional, não dependerá, portanto, do reconhecimento de uma condição individualizada ou especial. Esta natureza flexível da definição de deslocados internos é de grande relevância para o estudo de sua proteção jurídica já que estes devem desfrutar de seus direitos independentemente de seu status jurídico.

Apesar da definição proposta pela ONU, outros organismos internacionais conceituam o deslocado de forma diferente. O Conselho Permanente sobre Deslocados Internos nas Américas (CPDIA) define deslocados internos como apenas aquelas pessoas que, caso cruzem uma fronteira nacional internacionalmente reconhecida, adquirem status de refugiados. Já o Comitê Internacional da Cruz Vermelha (CICV), mesmo reconhecendo a validade da definição proposta nos Princípios Orientadores da $\mathrm{ONU}$, utiliza em seu trabalho de campo a definição que restringe as causas de deslocação interna a situações de conflito armado, seja ele internacional ou interno (GRUBBA; MAFRICA, 2015). Para fins de discussão, utilizar-se-á o conceito proposto pela ONU.

No caso Palmares/PE, alguns pontos devem ser destacados para definir se o evento extremo propiciou a movimentação populacional e se esta pode ser configurada como refugiados e/ou deslocados ambientais. Segundo Reuveny (2007), existe uma miríade de variáveis que podem ser observadas na classificação do deslocamento populacional. Um fator que Reuveny (2007) confere destaque é a assistência prestada pelo Poder Público no denominado pós-evento. Em linhas gerais seria o que foi feito pelos Governos (federal, estadual e municipal) de modo a amenizar os efeitos do desastre natural. Tais medidas influenciam diretamente a maneira como a população vai enfrentar o evento extremo.

O Governo de Pernambuco, a época, decretou estado de Calamidade Pública no município, seguindo os critérios definidos no Decreto Federal no 7.257/2010. Além disso, anunciou a construção de cinco barragens que possuíam como objetivo amenizar os efeitos de novas enchentes. De imediato criou-se o "Gabinete de Gestão da Crise" coordenado pelo Governador do estado juntamente com 15 secretarias em parceria com o Ministério Público de Pernambuco, o Poder Judiciário e o Tribunal de Contas do Estado. No mais, foi concebida a denominada "Operação Reconstrução" que teve como objetivo restaurar a infraestrutura das cidades atingidas e auxiliar a população com liberação de recursos financeiros e materiais (PERNAMBUCO, 2011).

Os custos com perdas e danos decorrentes da enchente foram de $\mathrm{R} \$ 3,4$ bilhões, sendo mais de $60 \%$ desse valor gasto com habitação (BANCO MUNDIAL, 2010). Ainda de acordo com o Banco 
Mundial (2010), apesar da magnitude do desastre, a rápida ação do estado minimizou os danos humanos e foram registradas 20 mortes (em Pernambuco) como consequência do evento.

O outro ponto que Reuveny (2007) traz a baila para análise é que a população do local afetado pode assumir, influenciada pelo modo pelo qual o Poder Público reage ao evento, três atitudes distintas: (1) Ficar no local e não fazer nada, aceitando os custos; (2) Ficar no local e minorar as mudanças ocorridas com o evento; e (3) deixar as áreas atingidas. As duas primeiras em razão de não existir o efetivo deslocamento da população não podem ser utilizadas para configurar casos de refúgios e/ou deslocados ambientais. Contudo, cabe salientar que para o autor, a terceira postura é amplamente praticada em países em desenvolvido devido a sua baixa capacidade de reação (estrutural) aos desastres ambientais.

Nota-se, pelas iniciativas empreendidas pelo Poder Público, que o objetivo foi recuperar os espaços afetados pela enchente, minimizando os efeitos decorrentes do evento extremo de modo que a população tivesse um ambiente propício para o reestabelecimento das suas atividades. Inclusive, parte dos equipamentos urbanos, juntamente com os conjuntos habitacionais das vítimas da enchente, foram reconstruídos em pontos mais altos da cidade.

Ademais, a própria conjuntura do desastre natural, que afetou várias cidades da mesma região, impede que os habitantes afetados pela enchente pudessem se deslocar para outras regiões. Além disso, as pessoas mais atingidas pela elevação do rio (Figura 7) foram aquelas que viviam as suas margens, possuindo uma condição econômica precária.

Figura 7. (A) Pessoas saindo de suas residências em razão das chuvas em Palmares/PE (19/06/2010); (B) Proximidade da ocupação do solo (residências) em relação às margens do Rio Uma em Palmares/PE.
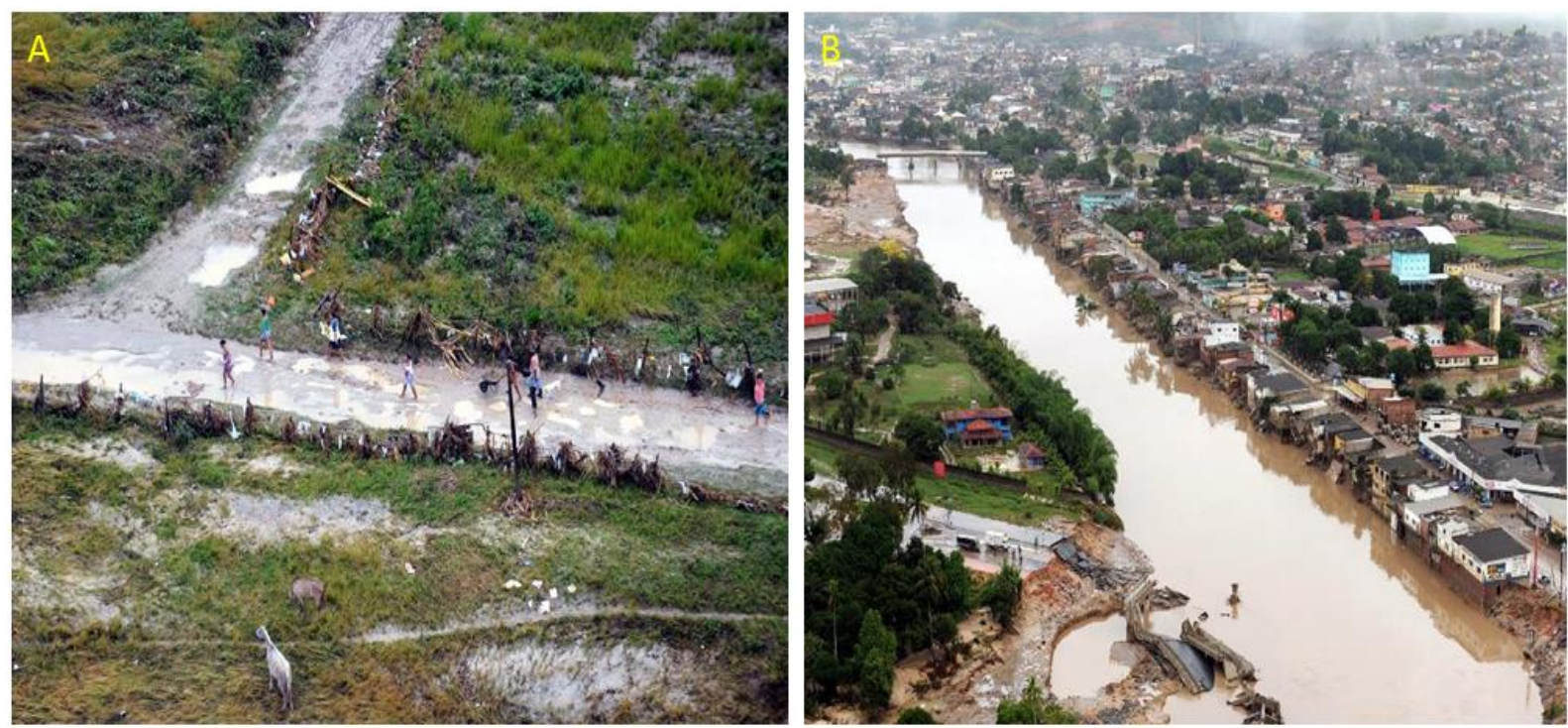

Fonte: EBC (2010). 
Por conseguinte, seguindo a classificação de Reuveny (2007), a postura adotada pela população e estimulada pelo Poder Público foi a de número dois, ou seja, ficar no local e minorar as mudanças decorrentes do desastre. Entretanto, não se pode desconsiderar que uma parcela da população optou por não permanecer na cidade. Nesse sentido não é despiciendo fazer uma breve análise sobre esse movimento.

Pensar em uma deslocação de refugiados ambientais decorrentes das chuvas ocorridas em Palmares/PE esbarra tanto no aspecto geográfico do munícipio, que não está próximo de nenhuma fronteira internacional, quanto na condição financeira das pessoas diretamente atingida pelo evento extremo (BANCO MUNDIAL, 2010). As pessoas que não permaneceram na cidade, quase em sua totalidade, não saíram de Pernambuco, deslocando-se para outras regiões do estado (BONIN, 2010; CAVALCANTE, 2015; RODRIGUES, 2010). Isto posto, seguindo as definições propostas pela ONU, esses indivíduos que deixaram sua residência em decorrência das chuvas são considerados deslocados ambientais, merecendo, pois, uma atenção maior em razão do seu estado de vulnerabilidade socioambiental.

\section{CONCLUSÃo}

As mudanças climáticas despontam como um dos principais desafios a serem enfrentados na contemporaneidade seja em razão das suas consequências físicas seja pelos impactos sociais que delas advém. Não obstante tal problemática, a imprevisibilidade dos eventos extremos traz consigo a ideia de prevenção amplamente discutida pelas ciências ambientais, pois através dessa prática as perdas podem ser minimizadas na chamada sociedade do risco.

No estudo sobre Palmares/PE pode-se verificar o quanto repentino pode ser um evento meteorológico. Em poucos dias a cidade foi consumida pelas águas do rio Una, trazendo consequências que são sentidas até hoje pela sua população. Grande parte dos indivíduos decidiu permanecer na cidade em razão do apoio do Poder Público no que cabe a reconstrução do munícipio, todavia alguns foram obrigados a sair em razão do medo ocasionado pelo episódio vivenciado em junho de 2010 . Esses que se distanciaram do seu local de origem por razões ambientais são considerados deslocados ambientais de Palmares/PE.

Quando se trata das modificações do clima e da situação dos refugiados/deslocados ambientais, têm-se realidades diversas; contextos globais, regionais e locais. Portanto, a abordagem multidimensional dos eventos extremos, de suas consequências para as populações humanas, precisa abarcar fatores meteorológicos, climáticos, ecossistêmicos, socioculturais e econômicos dos acontecimentos, no intuito de fazer compreender, profundamente, a problemática e dirimir as possíveis negligências. 
Destarte, reunindo e interconectando em um mesmo texto conhecimentos climatológicos, meteorológicos, históricos, sociais e jurídicos, com o intuito de, não só, analisar o evento que aconteceu em Palmares, mas de produzir, criticamente, um conhecimento sobre o Direito Ambiental no contexto das mudanças climáticas, é que se pratica, teórico-metodologicamente a interdisciplinaridade.

\section{REFERÊNCIAS}

ABDN. Atlas Brasileiro de Desastres Naturais 1991 a 2010: volume Brasil. Centro Universitário de Estudos e Pesquisas sobre Desastres. Florianópolis: CEPED UFSC, 2012. Disponível em: <http://150.162.127.14:8080/atlas/Brasil\%20Rev \%202.pdf>. Acesso em: 24 de Abril de 2016. AGÊNCIA PERNAMBUCANA DE AGUAS E CLIMA (APAC). Monitoramento pluviométrico. Disponível em:

<http://www.apac.pe.gov.br/meteorologia/monito ramento-pluvio.php>. Acesso em: 20 de junho de 2016.

ALMEIDA, A. B. Gestão da água, incertezas e riscos: conceptualização operacional. Coleção Água, Ciência e Sociedade. Associação Portuguesa dos Recursos Hídricos. Lisboa: Esfera do Caos Editores, 2011.

BARBOSA, V. V., SOUZA, W. M., GALVÍNCIO, J. D., COSTA, V. S. O. Análise da variabilidade climática do município de Garanhuns, Pernambuco - Brasil. In: Revista Brasileira de Geografia Física, v. 09, n. 02, 2016.

BANCO MUNDIAL. Avaliação de Perdas e Danos: Inundações Bruscas em Pernambuco. Davos: Banco Mundial, 2010.

BRASIL. Lei 12187, 29 de dezembro de 2009. Política Nacional sobre a Mudança do Clima. Disponível em: http://www.planalto.gov.br/ccivil_03/_ato2007201 0/2009/lei/112187.htm. Acesso em: 22 de abril de 2016.

BECK, U. Sociedade de risco: rumo a uma outra modernidade. São Paulo: Ed. 34, 2010.

BONIN, R. Dois meses após enchente, Palmares, em PE, ainda retira lodo das ruas. In: Portal G1. 2010. Disponível em: <http://g1.globo.com/especiais/eleicoes2010/noticia/2010/09/dois-meses-apos-enchentepalmares-em-pe-ainda-retira-lodo-das-ruas.html>. Acesso em: 01 de junho de 2016.

BUCCHIGNANI, E.; GUTIERREZ, J.M. Definition of different EWIs, to support the management of European CI. INTACT Deliverable D2.1, project cofunded by the European Commission under the 7th Frame-work Programme, 2015.Disponível em: http://www.intact-

project.eu/intact/assets/File/wp/D2_1_Definition_
of_different_EWIs.pdf. Acesso em: 25 de abril de 2016.

CAVALCANTE, P. Em PE, G1 visita Palmares para ver o que mudou após enchentes de 2010. In: Portal G1. 2010. Disponível em: < http://g1.globo.com/pe/caruaru regiao/noticia/2015/06/em-pe-g1-visita-palmarespara-ver-o-que-mudou-apos-enchentes-de 2010.html> . Acesso em 01 de junho de 2016. COMISSÃO DE DIREITOS HUMANOS. Report of the Representative of the Secretary-General, Francis Deng, submitted pursuant to resolution 1997/39 (The Guiding Principles on Internal Displacement), doc. E/CN.4/1998/53/Add.2. Disponível em: <www.un.org> Acessado em: 10/06/2016.

EMPRESA BRASIL DE COMUNICAÇÃO (EBC). Enchentes em Palmares/PE. Disponível em: $<$ http://tvbrasil.ebc.com.br/outroolhar/episodio/o utro-olhar-enchente-em-palmares-pe>. Acesso em: 15 de junho de 2016.

GRUBBA, L.S.; MAFRICA, C.A.S. A proteção internacional aos refugiados ambientais a partir do caso Kiribati. In: Veredas do Direito, v.12, n.24, p.207 226, 2015.

IBGE. Censo demográfico 2010. Disponível:

//http://www.ibge.gov.br/. Acesso: 30 maio 2016. INTERGOVERNMENTAL PANEL ON CLIMATE CHANGE (IPCC).Climate Change 2014: synthesis report. Contribution of Working Groups I, II and III to the Fifth Assessment Report of the Intergovernmental Panel on Climate Change [ Core Writing Team, R.K. Pachauri and L.A. Meyer (eds.)]. Geneva, Switzerland, $2014 . \quad$ Disponível em: <http://www.ipcc.ch/report/ar5/syr/>. Acesso em: 23 de abril de 2016.

MARENGO J. A. Impactos de extremos relacionados com o tempo e o clima - Impactos sociais e econômicos. In: Boletim do Grupo de Pesquisa em Mudanças Climáticas -GPMC. Edição Especial, Número 8 - Maio, 2009. Disponível em: $<$ http://mudancasclimaticas.cptec.inpe.br/ rmclim a/pdfs/newsletters/Boletim_No8_Port.pdf $>$. Acesso em: 3 de maio de 2016.

MILARÉ, É. Direito do Ambiente: Gestão Ambiental em foco. 10 ed. Rio de Janeiro: RT, 2015. 
OLIVEIRA, E.C. A proteção jurídica internacional dos deslocados internos. In: Veredas do Direito, v.8, n.15/16, p.77-88, 2010.

PACÍFICO, A.P.; GAUDÊNCIO, M.R.B. A proteção dos deslocados ambientais no regime internacional dos refugiados. In: REMHU - Rev. Interdiscip. Mobil. Hum, n. 43, p. 133-148, 2015.

PERNAMBUCO. Plano Estadual de Mudanças Climáticas. Recife: SEMAS, 2011.

RAMOS, A. RODRIGUES, G., ALMEIDA, G.A. 60 anos

de ACNUR : perspectivas de futuro. São Paulo :

Editora CL-A Cultural, 2011.

REIS NETO, A.F. Potencialidades e limitação para aplicação da Redução do Desmatamento e da Degradação Florestal (REDD) na mata atlântica pernambucana. Dissertação (Mestrado pelo Programa de Pós-graduação em Desenvolvimento e Meio Ambiente) - Universidade Federal de Pernambuco, Recife, 2016.

REUVENY, R. Climate change-induced migration and violent conflict. Political Geography, n 26, p. 656-673, 2007.

RODRIGUES, J.C. Municípios nordestinos castigados por enchentes começam a se reerguer, diz ministro.
In: EBC. 2010. Disponível em: $<$ http://memoria.ebc.com.br/agenciabrasil/noticia /2010-06-29/municipios-nordestinos castigadospor-enchentes-comecam-se-reerguer-diz-ministro>. Acesso em 02 de junho de 2016.

SOUZA, I.A.; MACIEL NETTO, A.; AZEVEDO, J.R.G. Impacto do aquecimento global no balanço hídrico diário e suas consequências para a agricultura. In: Revista Brasileira de Geografia Física, v. 03, p. 558571, 2012.

SOUZA, J. C. Um ensaio sobre a problemática dos deslocados ambientais: a perspectiva legal, social e econômica. In: Veredas do Direito, v.7, n.13/14, p.57$73,2010$.

STEPHESON, D. B. Definition, diagnosis, and origin of extreme weather and climate events, 2008. Disponível em: <http://empslocal.ex.ac.uk/people/staff/dbs202/p ublications/2008/extremes.pdf $>$. Acesso em: $23 \mathrm{de}$ abril de 2016.

WESTRA, L. Environmental Justice and the Rights of Ecological Refugees. London: Earthscan, 2009. 